\title{
Spinoza, un realismo anómalo de la paz
}

\section{Spinoza, an anomalous realism of peace}

\author{
Diego Tatián ${ }^{1}$ \\ Universidad Nacional de Córdoba / CONICET (Argentina)
}

Recibido: 03-06-14

Aprobado: 01-07-14

\section{Resumen}

Pensada en sentido spinozista, la paz no se construye contra el derecho natural sino con él y como resultado de él; no implica su cancelación sino su redireccionamiento, su politización. Remite a una ontología política que desmantela tanto la idea del buen gobierno concebido en cuanto gobierno de un príncipe dotado de virtudes privadas, como la alienación en cualquier instancia puramente jurídica establecida merced a una lógica trascendente. El "arte de la concordia" necesario debido al carácter natural de las pasiones humanas que una filosofía de la paz no quimérica deberá tomar por punto de partida, se articula por consiguiente a una "ciencia de los afectos", expresión que Spinoza opone a la denostación de los asuntos humanos propia del "odio teológico" y al ars vituperandi que anima la retórica del pecado.

Palabras-clave: Spinoza, Paz, Guerra, Virtud, Democracia.

\begin{abstract}
In a Spinosist way, peace is not constructed against natural law, but within it and as its result. It does not imply law's cancellation, but its redirection, its politicization. Peace thus evokes a political ontology that takes down both the idea of good government -conceived in the sense of the government of a prince who is given with private virtues-, and the alienation in any purely juridic instance,

\footnotetext{
${ }^{1}$ (diegotatian@gmail.com). Diego Tatián es profesor de filosofía política en la Universidad Nacional de Córdoba e investigador de CONICET (Argentina). Ha sido director de la editorial de la Universidad y actualmente es decano de la Facultad de Filosofía y Humanidades de la misma universidad. Sus últimas publicaciones son: La conjura de los justos. Borges y la ciudad de los hombres (2010), Spinoza. El don de la filosofia (2012), Baruch (2012), Lo impropio (2013), Spinoza. Filosofía terrena (2014), Los seres y las cosas (relatos, 2014).
} 
established by means of a transcendent logic. The "art of concord", which is necessary due to the natural character of human passions that a non chimeric peace based philosophy shall take as departing point, is then articulated with an "affection science". Spinoza opposes this last expression to the theological hate's characteristic outrage on human matters, and to the ars vituperandi that encourages a sin's rhetoric.

Key-words: Spinoza, Peace, War, Virtue, Democracy.

I.

Si la Ética puede ser concebida como una filosofía de la paz que concierne a la existencia de los seres humanos en tanto partes de la naturaleza (y en cuanto tales sometidos a la acción antagonista de causas exteriores no convergentes con la plenitud del conatus singular -es decir sometidos naturalmente a una guerra de potencias inmediatamente contradictorias-), en el Tratado teológicopolítico la paz refiere sobre todo a la paz civil en el interior de un cuerpo político (la "paz de la república"'), mientras que el Tratado político agrega el problema de la paz exterior en tanto alianza entre cuerpos políticos diferentes. El sentido profundo del spinozismo aloja una filosofía política de la paz entre las ciudades que se halla en estricta continuidad con la paz interior de los Estados (bajo la forma democrática), con la pequeña física y con la ontología propiamente dicha.

En su introducción al Tratado político Charles Ramond establece un vínculo entre el concepto de "pacto", el concepto físico de "composición", el concepto religioso de "alianza", el "consentimiento" y el "equilibrio" en el registro afectivo, para indicar que en el spinozismo la existencia de toda entidad natural o política tiene por condición una "paz", en sentido extenso del término, que aquellas palabras designan. De manera que tendríamos en Spinoza una filosofía de la paz que desborda la dimensión política y se extiende a la realidad toda ${ }^{3}$. Democracia sería el precipitado último, la forma al fin hallada que expresa de la manera más plena esa ontología spinozista de la paz, no solamente como paz civil sino también como condición de la paz entre ciudades ${ }^{4}$ y como ámbito más favorable a la philautía, la amistad de los

${ }^{2}$ Tal y como es explicitado en el subtítulo del TTP: "Contiene varias disertaciones, en las que se demuestra que la libertad de filosofar no solo se puede conceder sin perjuicio para la piedad y para la paz del Estado, sino que no se la puede abolir sin suprimir con ella la paz del Estado e incluso la piedad" (Tratado teológico-político, versión de Atilano Domínguez, Madrid, Alianza, 1986, p. 60).

${ }^{3}$ Sobre las distintas dimensiones involucradas en la cuestión de la paz, ver Charles Ramond, Introduction a Spinoza, [en Spinoza, Oeuvres V. Tractatus politicus / Traité politique, texto establecido por Omero Proietti; traducción francesa, introducción, notas, glosarios, index y bibliografía de Charles Ramond, Paris, Presses Universitaires de France, 2005], pp. 36-39.

4 "Cuantas más sociedades firman un tratado de paz, tanto menos temible resulta cada una de 
hombres consigo mismos que resulta de un desbloqueo y una conciencia de su potencia de obrar y de pensar.

El lector del Tratado político experimenta sin embargo una particular desorientación ante la explícita conjunción de realismo y pacifismo que acompaña la tracción filosófica de este libro, y por la crudeza de algunos pasajes en el marco de una filosofía orientada por la cuestión de la paz - palabra que en sí misma no comulga con la tradición realista que prescribe la inexorabilidad de la dominación y la imposición por medio de la fuerza como la ley de hierro del vínculo entre los estados. El realismo anómalo de Spinoza explora esa conjunción y redunda en un materialismo de la paz despojado de las consideraciones morales que revelan su ineficacia frente a los asuntos humanos. Uno de esos pasajes, cuya crueldad ha llamado la atención de los estudiosos de esta obra y sus lectores en general, es la conclusión de TP, IX, 13: “...las ciudades conquistadas en guerra y anexadas al Estado deben ser consideradas aliadas del Estado y unidas por beneficios; o si no deben enviarse a ellas colonias con derecho de ciudadanía, exterminándose o trasladándose a otro lugar a sus poblaciones" ${ }^{5}$-texto que reitera lo dicho en TP, VI, $35^{6}$. Además de remitir en su redacción a Las troyanas de Séneca -según ha mostrado la crítica filológica de Omero Proietti ${ }^{7}$ - con toda probabilidad se trata de una cita oculta de Discorsi sopra la prima deca di Tito Livio, II, 23, donde Maquiavelo aconseja el beneficio o la destrucción de las ciudades conquistadas pero nunca el camino intermedio ${ }^{8}$-argumento central

ellas a las demás. En otros términos, menos poder tiene cada una de hacer la guerra y más obligada se siente a observar las condiciones de la paz" (Tratado político, traducción de Atilano Domínguez, Madrid, Alianza, 1986, cap. III, § 16. En las subsiguientes referencias a este libro se emplea siempre esta edición).

${ }^{5}$ Ibid., p. 208.

6 "No se debe hacer la guerra sino en vistas a la paz, de suerte que, terminada la guerra, se depongan las armas. Una vez tomadas las ciudades por derecho de guerra y sometido el enemigo, se deben fijar, pues, unas condiciones de paz. Su objetivo será que las ciudades tomadas no exijan una guarnición permanente, sino que o bien se conceda al enemigo que, tras aceptar un tratado de paz, las rescate por un precio o que (si, de esa forma, siempre subsistiría un temor por la espalda [timor semper a tergo], debido a la situación estratégica del lugar) se las destruya totalmente y se lleven sus habitantes a otra parte" (ibid., p. 138).

${ }^{7}$ Omero Proietti, Notice sur la constitution du texte, [en Spinoza, Oeuvres V. Tractatus politicus / Traité politique, op.cit.], pp. 64-67. La expresión timor semper a tergo remite a Las troyanas, v. 530. El texto senequiano hace explícita esta necesidad de los vencedores tras la contienda: "La ansiosa esperanza de una paz incierta a los dánaos siempre sujetará; siempre, por la espalda, el temor (semper a tergo timor) los obligará a mirar atrás las armas, y no les permitirá deponerlas, mientras a los abatidos frigios, Andrómaca, vuestro hijo les dé ánimos" [vv. 529-533]. Por ello es que la ciudad "ahora polvo elevado es, todo fue abatido con fuego y, de la vasta urbe, ni siquiera subsiste algo en donde se esconda un niño" [vv. 478-482] (Séneca, Tragedias / Tragoediae, tomo I, edición bilingüe, introducción, traducción y notas de Germán Viveros, Universidad Nacional Autónoma de México, 1998 , pp. 66 y 68).

8 "...fueron ciudad por ciudad, rescataron las que eran importantes, y las beneficiaron o las destruyeron, haciendo a las beneficiadas exenciones y privilegios... y, a las otras, las arrasaron enviándoles colonias, y las sometieron a Roma, dispersándolas de tal modo que ya no podían perjudicarlos con las armas ni con los consejos... Cuando debe juzgarse a ciudades poderosas, y que están habituadas a vivir libres, conviene derrotarlas o acariciarlas porque, de otro modo todo juicio 
del acervo realista que seguramente encuentra su documento más antiguo y más impresionante en el diálogo de los atenienses con los melios relatado por Tucídides en el libro V de la Historia de la guerra del Peloponeso ${ }^{9}$.

II.

Este singular realismo que parte de la naturalidad de las relaciones de fuerza y la facticidad de la dominación es el fondo -insuprimible en su materialidaddesde el que Spinoza piensa una filosofía de la paz despojada de todo cuño idealista o moralista, que no soslaya las dificultades de la pasionalidad humana ni la condición natural de la hostilidad. Más bien parte de ellas bajo el precepto de que la guerra no es "un vicio en el que los hombres caen por su propia culpa...", sino un régimen afectivo dado que se trata de desviar hacia otro régimen de afectos que no suprime los conflictos sino que hace algo con ellos; una filosofía de la paz para este mundo de seres humanos tal y como son, y no para un mundo de seres humanos tal y como deberían ser -que sería un mundo puramente imaginario en el que, por lo demás, no es necesaria ninguna filosofía de la paz. Así concebida -de manera activa, en tanto virtud- la paz no se define por una ausencia sino por un cierto modo de darse de los conflictos, de las pasiones, de la multiplicidad y el ejercicio de la potencia común, que los inscribe en un conjunto de mediaciones y en una politicidad precisa designada por Spinoza con la antigua palabra griega democracia.

El spinozismo político revela el vínculo lógico que mantiene unidas la monarquía con la guerra y la democracia con la paz. El origen del poder monárquico y el secreto de su perseverancia es efectivamente la guerra y las

es vano. Y se debe escapar completamente del camino intermedio...”, etc. (Maquiavelo, Discursos de la primera década de Tito Livio, versión de Roberto Raschella, Buenos Aires, Losada, 2003, pp. 281-285).

9 Se trata de uno de los más célebres manifiestos del "realismo político" antiguo. Melos era una isla-Estado cuyos habitantes no querían someterse a Atenas como las demás islas, sino que, al principio, permanecían neutrales. Pero no sólo los melios -revela el texto- deberán soportar el peso de la necesidad; también los atenienses, obligados a extender su imperio o perderlo, aducen que permitir la neutralidad constituiría "una clara señal de debilidad ante nuestros súbditos, en tanto que vuestro odio es expresión de poder". Cuando los generales atenienses afirman que "los hombres dominarán siempre a aquellos que sobrepujen en poder", no sólo dejan constancia de un deseo de gloria sino también de la más elemental necesidad de la política que rige las relaciones entre los Estados: dominar o someterse. Si no conquistaran ahora que pueden hacerlo -argumentan-, manifestarán así su debilidad y alentarán que otras naciones crezcan y los ataquen. De este modo, "por una necesidad de la naturaleza" (expresión que siglos después Hobbes, traductor de Tucídides, hará también suya) deben conquistar cuanto les sea posible. La necesidad que plantean los atenienses a los melios es la de "someterse o ser destruidos". Finalmente los magistrados melios se niegan a rendirse y los atenienses sitian la isla sin que los espartanos acudan en ayuda ("más que ningún otro pueblo conocido -les habían advertido- [los espartanos] consideran honroso lo que les gusta y justo lo que les conviene"). En el año - 416, después de varios meses de sitio, cae la ciudad y la población melia es exterminada por el ejército ateniense. 
pasiones que la circunstancia bélica promueve: el nacionalismo que produce un proceso de identificación colectiva con el mando; el miedo a la muerte por el enemigo que motiva una delegación pasiva de la propia protección, una alienación en el Uno y un consentimiento de la monarquía como ilusión de seguridad; el odio al extranjero que exacerba mecanismos de reducción a la identidad y la concentración del poder. De modo que una ecuación muy precisa cuyos términos son el miedo a (en) la guerra y el estado de "soledad" (lo que Kant llamaba "paz de los cementerios") es lo que permite explicar la constitución socio-afectiva de la monarquía. A distancia de la burla, la lamentación y el denuesto, el trabajo filosófico y político de construir la paz es la tarea misma de la democracia -que será ineficaz si se concibe como un puro régimen procedimental e instrumental y no pone en marcha la pregunta que interroga por los afectos con los que debe aliarse el pensamiento común, lo que Spinoza llamaba "Razón”. Esa pregunta es esta: ¿cuáles son los afectos de la democracia y cuáles son los afectos de la paz?

\section{III.}

El Tratado político atesora tres novedades manifiestas que establecen su singularidad y su productividad en el pensamiento político contemporáneo: ruptura con el contractualismo (si bien es cierto que, como señala Pierre-François Moreau, a la luz del TP esta ruptura puede advertirse ya en el paso del cap. XVI al cap. XVII del $\mathrm{TTP}^{10}$ ); acuñación del concepto de multitud; maquiavelismo explícito. Estos aspectos no son entre sí independientes, más bien presentan una conexión estrecha para constituir una perspectiva radical-democrática que adopta una posición realista contra el moralismo de los filósofos ("no han ideado jamás una política que pueda llevarse a la práctica") denunciado en la primera página del texto, a la vez que una afirmación de común libertad contra el cinismo de los políticos ("más bien hábiles que sabios"; "guiados por el miedo más que por la razón”) señalado inmediatamente después. La vía seguida por el TP para concebir algo atinente a los asuntos humanos "que sea compatible con la experiencia o con la práctica" y que pueda "resultar útil a la sociedad en general" toma igual distancia del moralismo de los filósofos y el cinismo de los políticos en favor de una "ciencia de los afectos"11 (motivo central de la Ética, que había sido desplazado en el TTP y recupera ahora su preeminencia teórica al punto de ser la primera palabra del TP, que comienza: "Affectus, quibus conflictamur, concipiunt philosophi veluti vitia, in quae homines sua culpa

\footnotetext{
${ }^{10}$ Pierre-François Moreau, Notice sur la réception $d u$ Traité politique [en Spinoza, Oeuvres $V$. Tractatus politicus / Traité politique, op. cit.], p. 79.

11 Sobre la "ciencia de los afectos", ver Marilena Chaui, Desejo, paixão e ação na Ética de Espinosa, São Paulo, Companhia das Letras, 2011, pp. 101-132.
} 
labuntur..." ["Los filósofos conciben los afectos, cuyos conflictos soportamos, como vicios en los que caen los hombres por su culpa..."]), cuya premisa de trabajo encuentra su formulación más elemental y más lacónica en TP, I, 4: "me he esmerado en no ridiculizar ni lamentar ni detestar las acciones humanas, sino en entenderlas (...humanas actiones non ridere, non lugere, neque detestari, sed intelligere...)". Deducir la política de "la condición común de los hombres" -y no de virtudes privadas de las que debieran estar dotados los seres humanos (tanto los que mandan como los que obedecen) si fueran tales y como deberían ser- se inspira en el propósito fundamental de la tradición política del realismo clásico: dotar de estabilidad a los asuntos públicos. Ello presupone por un lado confiarlos a un sistema de instituciones comunes en vez de su delegación en presuntas virtudes privadas de quienes se hallarían por naturaleza dotados para el mando, y por otro precaverse del daño ocasionado a la vida civil por los que "sueñan con el siglo dorado de los poetas o con una fábula" (TP, I, 5) al creer que la multitud se guía por la templanza, la razón y la justicia.

Política, pues, no es el reino de las razones (que -dice Spinoza- prospera en la debilidad, o in articulo mortis cuando el hombre yace inerte vencido por la enfermedad, o en el templo -es decir donde no hace falta ninguna política-), sino el imperio de los afectos y el dominio de las pasiones, cuyo poder se manifiesta en los tribunales y en los palacios (in foro, vel in aula) -en la communis vita. Por tanto, la necesidad de la política es directamente proporcional a la impotencia de la moral para regular la vida humana en común, dominada por las estructuras elementales del conatus y por la finitud -es decir por el poder que sobre las criaturas ejerce la exterioridad de la fortuna con la que están condenadas a lidiar. Tratar los afectos "con la misma libertad de espíritu que suele emplearse en las investigaciones matemáticas" -en vez de considerarlos como vicios en los que "los hombres caen por su culpa"- es la operación desmoralizadora y naturalizadora que había sido también el propósito de Ética III. Las pasiones no son una perturbatio en el orden de las cosas sino un efecto propio y necesario de los modos finitos en cuanto partes de la naturaleza; las marcas del occursus que las cosas tienen con las cosas por el hecho de ser tales (pues ser es siempre ser con otros, en medio de otros definidos por una capacidad de producir efectos); las excedencias de encuentros no siempre favorables a sus términos. La naturalización spinozista de las pasiones deriva de la teoría del derecho natural subjetivo -que comparte con Hobbes-, según la cual los seres humanos no se definen por la razón sino por el deseo y el poder, y su formulación se precisa en la ecuación jus sive potentia. Así pues el derecho natural de cada cosa (esto es, el poder por el que las cosas naturales existen, actúan y se conservan) se extiende hasta donde se extiende su potencia (tantum juris, quantum potentia); es "la mismísima potencia de Dios" (ipsissima Dei potentia) que se manifiesta inmediatamente como un apetito y como una vis 
- una fuerza de existir con la que están dotados todos los seres de la naturaleza.

El derecho (jus) nunca prohíbe, es afirmativo siempre, expresa en cualquier caso una potencia, mayor o menor, y por consiguiente "no se opone a las riñas, ni a los odios, ni a la ira, ni al engaño, ni absolutamente a nada de cuanto aconseje el apetito" (TP, II, 8) -antes bien se manifiesta positivamente de ese modo, aunque en su grado más elemental. El derecho natural accede a su plenitud cuando los seres humanos adoptan la guía de la razón, que en Spinoza surge siempre en el curso de un proceso colectivo y social.

Sobre este fondo de continuidades y rupturas, la paz como virtud sólo es posible en Spinoza porque toda sociedad se constituye y establece sobre un derecho natural, que permanece incólume y no desaparece en el estado social ${ }^{12}$. De manera que una sociedad no presupone la inmunización respecto al derecho natural; es más bien su colectivización y su continuación por otros medios -continuación que según veremos lo extiende e incrementa-, lo que equivale a decir que no es un imperio dentro de otro imperio, y que la razón nada exige que vaya contra la naturaleza (TP, III, $\S \S 8-9)$. El estado político spinozista, en suma, no es resultado de un pacto de cancelación del poder natural, ni una anulación del derecho por la ley -según la célebre distinción hobbesiana que consta en el cap. XIV del Leviatán ${ }^{13}$-, sino la autoinstitución colectiva ininterrumpida de ese derecho, del que la sociedad común es sólo el avatar más pleno. Spinoza lo repite en el capítulo III del TP -fundamental, como veremos, para su filosofía de la paz-: “...el derecho natural de cada uno (si lo pensamos bien) no cesa en el Estado político". Dicho de otro modo -y es este uno de los puntos de ruptura con el contractualismo hobbesiano-, en el estado de naturaleza el derecho natural (es decir el poder de perseverar) es mínimo y su fragilidad máxima, en tanto que en el estado político el derecho natural se incrementa de manera variable conforme la sociedad de la que se trate: es máximo en una democracia y menor bajo lo que Spinoza llama imperium violentum - no obstante lo cual, aún en este último caso, será mayor que en la situación presocial. El derecho natural casi no existe, pues, si no es como un derecho común y en tanto efecto de una composición a la que es directamente proporcional en su extensión ${ }^{14}$.

${ }^{12}$ Cfr. la célebre y tantas veces citada carta 50 a Jarig Jelles: "Por lo que respecta a la política, la diferencia entre Hobbes y yo, por la cual me pregunta usted, consiste en que yo conservo siempre incólume el derecho natural y en que yo defiendo que, en cualquier Estado (civitate), al magistrado supremo no le compete más derecho sobre los súbditos que el que corresponde a la potestad con que él supera al súbdito, lo cual sucede siempre en el estado natural" (Spinoza, Correspondencia, versión de Atilano Domínguez, Madrid, Alianza, 1988, p. 308).

13 "Aunque quienes se ocupan de estas cuestiones acostumbran confundir jus y lex, derecho y ley, es preciso distinguir esos términos, porque el derecho consiste en la libertad de hacer o de omitir, mientras que la ley determina y obliga a una de esas dos cosas. Así, la ley y el derecho difieren tanto como la obligación y la libertad, que son incompatibles cuando se refieren a una misma materia" (Thomas Hobbes, Leviatán, versión de M. Sánchez Sarto, Madrid, Sarpe, 1983, p. 139).

14 "el derecho natural, que es propio del género humano, apenas si puede ser concebido sino allí donde los hombres poseen derechos comunes..., cuantos más sean los que así se unen (quo plures in 
La filosofía spinozista de la paz presenta una singularidad no sólo en relación a sus contemporáneos (en particular respecto a la paz concebida como pacto en Hobbes), sino también a buena parte de la gran tradición filosófica. En lo que sigue se buscará poner de manifiesto esa singularidad, que procura pensar las condiciones de la paz no en una despotenciación del cuerpo colectivo sino en su virtud -confiriéndole a este término toda la positividad original implícita en el concepto de vir. En cuanto efecto de un ejercicio del poder y no de su cancelación, se trata de una paz paradójica, que no presupone la indiferencia, ni la armonía, ni la mera tolerancia, y que se designa también con la palabra democracia.

IV.

Una primera distinción referida al conflicto y a la guerra, ha recorrido la historia de la filosofía toda y es la que remite a la dicotomía fundamental de stásis y pólemos, tal como la encontramos formulada, por ejemplo, en un pasaje del libro V de la Politeia platónica, que cito in extenso:

\begin{abstract}
"Me parece que si la guerra (pólemos) y la discordia (stásis) tienen dos nombres diferentes es porque son también dos cosas diferentes que se relacionan con distintos objetos. Y estos dos contenidos son, por una parte el ámbito de lo doméstico (o más bien: la parentela) y la comunidad de estirpe (lo allegado); por otra parte lo extranjero y la diferencia de sangre. Así, el nombre de stásis se aplica a la enemistad entre parientes y el de pólemos a la enemistad entre extranjeros... Los de raza griega son parientes y allegados entre sí y, en cambio, son ajenos y extranjeros para los bárbaros... Por lo tanto, cuando los griegos luchen con los bárbaros y los bárbaros con los griegos, diremos que están en guerra y que son enemigos por naturaleza, y es preciso dar el nombre de pólemos a esta enemistad; pero cuando luchan griegos contra griegos, hemos de afirmar que son en verdad amigos por naturaleza, pero que Grecia se halla circunstancialmente (accidentalmente) enferma y dividida, y será preciso dar el nombre de stásis a esta enemistad" (470b-c).
\end{abstract}

Entre pólemos (es decir la condición que corresponde a la enemistad por naturaleza) y philía (esto es la amistad por naturaleza), stásis designa una perversión, un desquicio, un estado contra natura. A la parentela y la comunidad de estirpe (los términos usados por Platón son sikeion y syngenés) debiera corresponder -y este es el principio fuertemente asumido de la filosofía política clásica- una condición de concordia [homónoia -que, según especifica Aristóteles en Eth. Nic. 1167b no es otra cosa que politiké philia-] y de amistad (philía $)^{15}$.

unum sic conveniunt) más derechos tienen todos juntos...” (TP, II, § 15).

${ }^{15}$ En el libro V de la Politika Aristóteles reflexiona acerca de las causas de las stáseis y de las métabolai perí tés politeías, con el objeto, precisamente, de prevenirlas y conferir al orden político 
Por tanto, en el universo ideológico griego los conceptos de amistad y de hostilidad remiten, en primer lugar, a la relación entre helenos y bárbaros; en segundo término a la relación intra-helénica entre las póleis; y por último a la relación entre frentes enemigos en el interior de las póleis singulares. Sólo en el primer caso la guerra puede decirse "por naturaleza". Esta acuñación griega del concepto de "enemigo natural" -empleado asimismo por Spinoza- será paradigmática en la reflexión occidental acerca de la política, el conflicto y la guerra $^{16}$.

Según la ficción filosófica que en el siglo XVII fue designada como "estado de naturaleza" -y en virtud de la antropología negativa que le es aneja-, la condición humana tal como resulta inmediatamente dada se halla dominada por la hostilidad y la guerra, y todo hombre es a priori -"por naturaleza"- un enemigo. Lo es todo aquel que no reviste la condición de súbdito. "En efecto -escribe Hobbes en Leviatán, I, 28- todos los hombres que no son súbditos, o bien son enemigos, o bien han dejado de serlo en virtud de algún pacto" -o dicho con palabras del De cive: "Enemigo es para alguien todo aquel que no le obedece ni le manda" 17 .

Instituido el estado civil, los castigos y las penas que establece la ley se extienden a los súbditos y sólo a ellos - no a los enemigos (y son tales quienes no reconocen el poder soberano, sea por no haber participado de su institución, sea por haberse colocado fuera de ella una vez producida). Al infligirse un daño cualquiera a un inocente que no es súbdito, si se hace para beneficio del Estado y sin violación de ningún pacto preestablecido, dice Hobbes, ello no constituye un quebrantamiento de la ley de naturaleza [impropiamente llamada de ese modo,

una estabilidad, una inmunidad contra la acechanza de la discordia. Por lo demás esto es general en la cultura política clásica: ignoti nulla cupido ("no hay ningún deseo de lo desconocido") decía Ovidio, como opuesto al rerum novarum cupiditas, esto es el deseo de cosas nuevas que opera una mutatio rerum -término ciceroniano empleado aún por Maquiavelo-, expresión que en el mundo antiguo correspondía a nuestro concepto de revolución. Sin embargo, la especificidad de este término consiste en algo que no presenta antecedentes en la cultura política antigua: la irrupción de la cuestión social. Sobre esto, véase el estudio de Pier-Paolo Portinaro, Materiali per una storicizzazione della coppia amico-nemico [en Gianfranco Miglio (coord.), Amicus (inimicus) hostis, Milano, Giuffrè Editore, 1992], pp. 221-310.

${ }^{16}$ En el caso de la filosofía política contemporánea, las nociones de conflicto y enemigo, serán emblemáticamente tematizadas por Das Begriff des Politischen de Carl Schmitt. "Enemigo -se lee allí- no es el competidor o el adversario en general. Enemigo no es siquiera el adversario privado que nos odia en base a sentimientos de antipatía. Enemigo es sólo un conjunto de hombres que combate al menos virtualmente, es decir, en base a una posibilidad real, y que se contrapone a otra agrupación humana del mismo género. Enemigo es únicamente el enemigo público, puesto que todo lo que se refiere a una agrupación similar, y en particular a un pueblo entero, se vuelve por eso mismo público. El enemigo es el hostis, no el inimicus en sentido amplio; el polémios, no el echthrós". Junto a las dicotomías entre "enemigo natural-enemigo accidental"; "enemigo público-enemigo privado"; "enemigo público-enemigo secreto"; "enemigo interno-enemigo externo", pueden mencionarse, a partir de la obra de Schmitt, las de "enemigo real-enemigo convencional"; "enemigo real-enemigo absoluto"; "enemigo abstracto-enemigo concreto", etc.

${ }^{17}$ Thomas Hobbes, Tratado sobre el ciudadano, edición de Joaquín Rodríguez Feo, Madrid, Trotta, 1999, p. 83. 
pues estrictamente hablando en la naturaleza no hay ley sino sólo derecho] que prohíbe [también este verbo es, por lo mismo, inadecuado] a todos los hombres, en sus venganzas, considerar cualquier cosa que no sea un bien futuro. Por el contrario, el castigo de un súbdito inocente -que el soberano tiene el derecho (en la medida en que tiene el poder) de llevar a cabo- sí quebranta esa ley de naturaleza: ningún bien para el Estado puede derivarse del castigo a un súbdito inocente. Ahora bien, quienes se rebelan no son súbditos sino enemigos y han de ser tratados por el Estado según esa condición. Contra los enemigos que el Estado determina como tales y a los que juzga capaz de ocasionar perjuicio, es legítimo hacer la guerra, infligir los actos de hostilidad y los daños que sean necesarios, o que simplemente se consideren convenientes.

La lógica hobbesiana de la hostilidad establece una transformación -una secularización- referida a la naturaleza de la hostilidad, por relación a su estatuto en la Respublica Christiana medieval, -donde el "enemigo externo" es determinado como infiel, y el "enemigo interno" como hereje. En este caso, el poder eclesial detenta a la vez el control de la devoción y la definición del enemigo, articulando ambas cosas. En el origen del Estado moderno reviste fundamental importancia el desplazamiento de la decisión concerniente a la hostilidad desde la esfera religiosa a la puramente política, estableciendo el derecho del poder político el monopolio legítimo de la decisión acerca de quién es el enemigo.

\section{V.}

En un pasaje del capítulo XVII del TTP -cuyo propósito mayor es el de separar filosofía y teología como condición para la libertas philosophandi, pero también para producir la autonomía de la esfera política-, Spinoza identifica en esa determinación teológica del hostes y la hostilidad, la clave -o una de las claves- de la "teocracia", en su caso referida al estudio de la historia del pueblo judío.

"Sólo Dios, pues, gobernaba sobre los hebreos y sólo su Estado se llamaba, con derecho, reino de Dios en virtud del pacto, y con derecho también se llamaba a Dios rey de los hebreos. Por consiguiente, los enemigos de ese Estado (imperii hostes) eran enemigos de Dios (hostes Dei)... Quien faltaba a la religión, dejaba de ser ciudadano y era tenido ipso facto por enemigo (hostis)... Por eso, pudo este Estado recibir el nombre de teocracia, puesto que sus ciudadanos no estaban sujetos a otro derecho que al revelado por Dios" $"$.

Conforme un proceso de desteologización de la política -y por tanto de

${ }^{18}$ Spinoza, Tratado teológico-político, op. cit., pp. 357-358. 
la enemistad- que se lleva a cabo en las filosofías políticas del siglo XVII, enemigo pasa a ser simplemente todo el que vive fuera de la ciudad y por tal motivo, sólo fáctico, desconoce su gobierno. No son únicamente las pasiones individuales las que determinan la hostilidad; no se trata pues del inimicus, del enemigo privado, sino del hostis, del enemigo público que por su sola situación existencial reviste una amenaza para la ciudad. En otros términos, "no es el odio sino el derecho el que hace al enemigo del Estado"19. Debido a la naturaleza y a ninguna otra cosa es que "la guerra se extiende en todas las direcciones", como diría Foucault. También hacia el interior. Las promesas, los pactos, los gestos de reciprocidad, las palabras de reconocimiento mutuo -es decir el completo régimen de signos que busca conjurar la irrupción de pasiones en la vida común para volver previsible el tiempo por venir- no transforman la naturaleza (tampoco lo hace el poder público, que solo debe garantizar la estabilidad de un orden); únicamente operan en ella una enmienda, una suspensión, un desvío. En este punto la filosofía política de Spinoza inscribe su ruptura. Ya el TTP -durante mucho tiempo considerado en su parte política tributario del contractualismo hobbesiano- revela su diferencia. En el capítulo XVII, que pareciera desdecir lo dicho en el anterior siguiendo una escritura paradójica y llena de tensiones, se marcan los límites de la transferencia anticipando de algún modo el anticontractualismo del TP.

\begin{abstract}
"Pues nunca los hombres cedieron su derecho ni transfirieron su poder, hasta el extremo de no ser temidos por los mismos que recibieron su derecho y su poder, y de no estar más amenazado el Estado por los ciudadanos, aunque privados de su derecho, que por sus enemigos. Aún más, si los hombres pudieran ser privados de su derecho natural, de suerte que en lo sucesivo no pudieran nada sin el consentimiento de quienes detentan el derecho supremo, éstos podrían reinar impunemente sobre los súbditos de la forma más violenta... Hay que conceder, pues, que cada uno se reserve muchas parcelas de su derecho, las cuales dependerán, por tanto, de su propia decisión y no de la ajena"20.
\end{abstract}

Multa sibi sui juris reservare. En buena parte intransferible, el poder permanece en la ciudadanía, razón por la cual el "miedo de las masas" -conforme la expresión de Balibar- cobra aquí el sentido de un genitivo objetivo.

El Tratado político radicalizará pues esta idea cuando recupera el tópico maquiaveliano de la "multitud armada", cuya conveniencia Spinoza enuncia al menos en cuatro ocasiones -todas en los capítulos referidos a la monarquía ${ }^{21}$. La multitud armada es la reserva que preserva la paz del

\footnotetext{
19 Ibid., p. 344.

${ }^{20} \mathrm{Ibid}$., p. 351. Se trata de una cita oculta de Tácito, que Spinoza reitera unas pocas páginas más adelante: "nunca se ha logrado que el Estado no estuviera más amenazado por los ciudadanos que por los enemigos, y que quienes detentan su autoridad, no temieran más a los primeros que a los segundos" (ibid., p. 354).

${ }^{21}$ Spinoza, Tratado político, VI, § 10; VII, § 2; VII, § 17; VII, § 22.
} 
estado, su autonomía y la libertad, advirtiendo Spinoza -como lo había hecho el "agudísimo florentino"- que la consecuencia natural de contratar ejércitos mercenarios es la ruina de esta libertad. En efecto, "los ciudadanos que han entregado a otros las armas y le han confiado la defensa de las ciudades, sencillamente le han entregado su derecho y se confían plenamente a su fidelidad", transferencia completamente desaconsejada conforme la perspectiva maquiaveliana adoptada en el TP. Esa "fidelidad" se encuentra sometida al mismo carácter voluble de las promesas, completamente ineficaces como artilugio para construir y mantener una paz, pues valerse de ellas es desconocer el derecho natural, en virtud del cual no puede decirse que un hombre o una sociedad "obra con engaño o perfidia, porque rompe su promesa tan pronto ha desaparecido la causa del miedo o de la esperanza" que llevó a contraerla. Por ello, "si una sociedad se queja de haber sido engañada, no tiene por qué acusar de mala fe a la otra sociedad aliada, sino sólo a sí misma de ignorancia” (III, § 14). Por lo demás, insiste Spinoza, “...ni la razón ni la Escritura enseñan que siempre haya que ser fieles a la promesa realizada" (III, § 17).

La multitud armada es la ciudadanía misma cuyo único propósito y retribución es la libertad, al igual que un hombre en estado natural se defiende sin otra compensación que la de resguardar su vida y su libertad. Por el contrario, la formación de ejércitos profesionales comporta la asignación de un sueldo fijo y creará una casta de hombres que "sólo conocen el arte de la guerra y que, en tiempos de paz..., no piensan más que en rapiñas, discordias intestinas y guerras... semejante Estado monárquico es, en realidad, un estado de guerra" (VII, § 22). De manera paradójica, para la preservación de la paz -Spinoza, recordemos, está hablando aquí del régimen monárquico- "todos deberán poseer armas (omnes arma habere teneantur)" (VI, § 10); por el contrario, entregarlas a otro vuelve frágil esa paz y acaba por suprimir la libertad.

El materialismo spinozista de la paz considera asimismo aspectos de orden institucional en virtud de los cuales, también en este caso, se preserva de confiar los asuntos públicos a virtudes privadas. Esta vez en el capítulo sobre la aristocracia, Spinoza se pregunta -manteniendo siempre la reflexión a distancia de cualquier moralismo- por los requisitos que deberá cumplir una organización política para preferir la paz en vez de la guerra, y concibe, de manera estrictamente material, un conjunto de condiciones institucionales orientadas a inhibir la guerra en favor de la paz, por las cuales ésta deberá volverse más ventajosa -en sentido estricto- que la guerra, en particular para quienes deben decidir acerca de ella. Ante todo, "las ganancias de los senadores deben ser tales que les resulte más ventajosa la paz que la guerra" (VIII, § 31 ). El costo de una paz cuya preservación redunde en un beneficio para síndicos y senadores es alto, pero siempre será menor que los costos de una guerra y, 
sobre todo, siempre menor que los gastos superfluos de la realeza en el régimen monárquico: “...hay que señalar -escribe Spinoza- que las Casas Reales exigen mayores gastos, sin que se destinen a defender la paz, y que nunca puede ser demasiado alto el precio con el que se obtenga la paz" (VIII, § 31).

VI.

Pensada en sentido spinozista, la paz -tanto civil como internacional, y que al igual que la seguridad y la libertad es uno de los fines del estado político (V, $\S 2)$ - no se construye contra el derecho natural sino con él y como resultado de su enmienda; no implica su cancelación sino su redireccionamiento, su politización. Se trata de una ontología política que desmantela tanto la idea del buen gobierno concebido en cuanto gobierno de un príncipe dotado de virtudes privadas $^{22}$, como la alienación en cualquier instancia puramente jurídica establecida merced a una lógica trascendente. El "arte de la concordia" 23 , necesario debido al carácter natural de las pasiones humanas que toda política no quimérica deberá tomar por punto de partida, se articula por consiguiente a una "ciencia de los afectos" -expresión que Spinoza opone a la denostación de los asuntos humanos propia del "odio teológico" y al ars vituperandi que anima la retórica del pecado.

El tránsito de la guerra a la paz, de la hostilidad natural al conflicto institucionalmente manifestado, se concreta de manera inmanente a partir de las pasiones mismas, es decir "a partir de la tendencia universal de todos los hombres a conservar su ser... [tendencia que] existe en todos, sean ignorantes o sean sabios" (TP, III, § 18), y por la cual -cuando se halla colmada por "afectos de odio" como la ira, la envidia, la venganza, etc.,- "los hombres son enemigos por naturaleza (sunt ergo homines ex natura hostes)" (TP, II, § 14). Al igual que lo son dos ciudades ${ }^{24}$ que no han inscripto su derecho natural en la lógica de la composición que los incrementa, según la misma modalidad conforme los

\footnotetext{
22 "[Ordenar] de tal suerte los asuntos del Estado, que nada cuanto se refiere al bien común, se confíe totalmente a la buena fe de nadie" (ibid., VI, §3).

${ }^{23} \mathrm{Ibid}$. En una nota de su edición del TP, Paolo Cristofolini afirma que aquí debemos entender "arte" en sentido renacentista, y en particular maquiaveliano (Spinoza, Trattato politico, Pisa, Edizioni ETS, 1999, p. 87).

${ }_{24}$ "Todo esto se puede comprender con más claridad, si consideramos que dos sociedades son enemigas por naturaleza (duae Civitates natura hostes sunt). Efectivamente, los hombres... en el estado natural son enemigos; y, por lo mismo, quienes mantienen el derecho natural fuera de la sociedad, son enemigos. Por tanto, si una sociedad quiere hacer la guerra a la otra y emplear los medios más drásticos para someterla a su dominio, tiene derecho a intentarlo, ya que, para hacer la guerra, le basta tener la voluntad de hacerla. Sobre la paz, en cambio, nada puede decidir sin el asentimiento de la voluntad de la otra sociedad. De donde se sigue que el derecho de guerra (Jura belli) es propio de cada una de las sociedades, mientras que el derecho de paz (Jura pacis) no es propio de una sola sociedad, sino de dos, al menos, que, precisamente por eso se llaman aliadas" (TP, III, §13).
} 
particulares se componen formando un poder colectivo -designado por el TP como potentia multitudinis.

Según el TP, en efecto, una "multitud libre" (libera multitudo) es el sujeto político capaz de alcanzar el propósito último de la experiencia política, que no es el de la mera conservación de la vida. El concepto spinozista de "perseverancia en el ser" es irreductible al puro "conservar" hobbesiano, por cuanto Spinoza jamás sacrifica la vida -que para ser humana debe ser libre- a su pura conservación. En un texto que marca, nuevamente, una ruptura con la analítica hobbesiana de la conservatio vitae -donde "vida" equivale a nuda vita-, escribe Spinoza: "Cuando decimos, pues, que el mejor Estado es aquel en que los hombres llevan una vida pacífica (concorditer vitam), entiendo por vida humana aquella que se define, no por la sola circulación de la sangre y otras funciones comunes a todos los animales, sino, por encima de todo, por la razón, verdadera virtud y vida de la mente" $(\mathrm{V}, \S 5)$.

La obra de la política no es la de "simplemente evitar la muerte" sino, de manera positiva, la de "cultivar la vida" (vitam colere) (V § 6) en cuanto vida humana. En otros términos, Spinoza está diciendo que el precio de la paz no puede, jamás, ser la libertad, porque en ese caso no se trataría de una paz. Por el contrario, en sentido spinozista la paz es siempre una obra de la libertad-una virtud. No una negativa evitación del summum malum sino una producción experimental y abierta del summum bonum. Una ausencia de conflicto que no redunda en libertad ni resulta de ella no equivale a la paz; para esa circunstancia Spinoza reserva el nombre de "soledad" (solitudo). Esto puede leerse en uno de los pasajes más impresionantes del TP: "De una sociedad cuyos súbditos no empuñan las armas, porque son presa del terror, no cabe decir que goce de paz, sino más bien que no está en guerra... Por lo demás, aquella sociedad cuya paz depende de la inercia de unos súbditos que se comportan como ganado, porque solo saben actuar como esclavos, merece más bien el nombre de soledad que el de sociedad (rectius solitudo, quam Civitas dici potest)" (V, § 4). La paz como virtud no es convertible con una mera ausencia de guerra; equidista de la guerra, la soledad y el mero pacto. Es decir: paz, no immunitas.

Asimismo, Spinoza destruye el clásico argumento -que puede ser remontado hasta Las leyes de Platón, donde es defendido contra la posición ateniense tanto por Clinias como por Megilo- según el cual el sentido de la política es la preparación para la guerra, por lo que la monarquía sería el régimen más apto. Se trata de un muy antiguo recurso de la ideología que llega hasta nuestros días, y es el que exige la esclavitud en la paz como precio del poder en la guerra -o dicho de manera más concisa: el que reclama el sacrificio de la libertad como condición de la seguridad. "Elegir -afirma Spinoza-, como se hace con frecuencia, a un rey con fines bélicos, porque los reyes dirigen con mucho más éxito la guerra, es una auténtica tontería, ya que, para mejor 
hacer la guerra, se hacen esclavos en la paz. Si es que cabe hablar de paz en un Estado en el que, sólo a causa de la guerra, se ha entregado a uno la suprema potestad, y es principalmente en la guerra donde éste puede manifestar su virtud personal... Por el contrario, la característica principal del Estado democrático (imperium Democraticum) consiste en que su virtud es mucho más eficaz en la paz que en la guerra" (VII, § 5).

Así, democracia es otro nombre que designa la paz como virtud y como construcción ininterrumpida de una condición común que deberá disipar lo que la experiencia parece enseñar. En efecto, ningún estado se mantuvo más tiempo ni estuvo menos afectado por conflicto que el turco; en tanto que los estados democráticos o populares -pareciera enseñarnos la experiencia-, son inestables y duran poco, debido a los conflictos que naturalmente se producen en ellos. "Claro que -añade Spinoza- si hay que llamar paz a la esclavitud, a la barbarie y a la soledad, nada hay más mísero para los hombres que la paz”. Por lo que "no es, pues, a la paz sino a la esclavitud a la que interesa que se entregue todo el poder a uno solo; ya que, como hemos dicho antes, la paz no consiste en la privación de la guerra, sino en la unión de los ánimos o concordia" (VII, § 4).

\section{VII.}

La concordia que Spinoza identifica aquí con la paz no presupone una pasividad, no es resultante del miedo ni equivalente a una mera tolerancia sino efecto de la vita activa, el reconocimiento y las nociones comunes; práctica ininterrumpida de una potentia democratica, colectiva e instituyente, que no transfiere su virtud política ni la depone ante instituciones puramente procedimentales, antes bien genera y anima de manera continua esas instituciones -que no son sino expresiones suyas. La virtud cívica de una multitud libre es condición de las instituciones públicas, incapaces como tales de crear la paz -mucho menos una paz perpetua. Porque las instituciones -entre ellas el orden jurídico interno e internacional- no son en sí mismas virtuosas sino expresiones $\mathrm{y}$ efectos de la virtud, la paz no puede nunca ser perpetua sino siempre una condición de los hombres producida por ellos y mantenida por una constancia -que como tal puede dejar de serlo y perderse la paz. Constancia pues de una potencia democrática constituida por una temporalidad plural ${ }^{25}$, dotada de un sentido kairológico capaz de intervenir oportunamente en la contingencia de los asuntos humanos, de inventar y producir cosas nuevas.

\footnotetext{
${ }^{25}$ Cfr. sobre esto los trabajos de Vittorio Morfino, en particular Il tempo e l'occasione. L'incontro Spinoza-Machiavelli, Il Filarete, Facoltà di Lettere e Filosofia dell'Universitá di Milano, 2002; también el conjunto de textos que componen Il tempo de la multitudine. Materialismo e politica prima e dopo Spinoza, Roma, Manifestolibri, 2005.
} 
En Spinoza la naturaleza no inhibe la invención ni cancela la historia; tampoco -como consta en el subtítulo del TTP-, la seguridad es diferente de una práctica de la libertad sino lo que resulta de ella; ni la constancia equivale a la pura repetición; ni, en suma, presupone la paz, en ningún sentido, una clausura de la vida política. Antes bien, la construcción de la paz se inscribe, como todas las cosas, en una ontología de lo necesario que permite una inteligencia emancipadora del mundo social, y se conjuga a la vez con la indeterminación de la aventura histórico-política: no sabemos, pues, lo que puede un cuerpo colectivo, ni de lo que es capaz como fuerza productiva de política cuando accede a su potencia -que en Spinoza es lo mismo que la virtud.

La paz se crea a cada instante; se mantiene, se sostiene y eventualmente se extiende por la acción común de los hombres. No encontramos en Spinoza una filosofía de la historia de sentido progresista que llegará a suprimir de una vez para siempre las contradicciones entre los pueblos y los conflictos entre seres humanos; tampoco una filosofía de la cultura que permita presumir un tránsito definitivo de la guerra hacia la paz, ni es dado albergar la esperanza en un conjunto jurídico de condiciones de posibilidad que podrá por sí mismo garantizar la abstención de la violencia e impedir su reinicio una y otra vez. La paz como virtud significa en Spinoza que es institución ininterrumpida, ejercicio de la potencia, dépense - $\mathrm{y}$ que no admite ser solo jurídicamente constituida, ni ser puramente formal ni perpetua. Conquista de la duración por medio de la acción colectiva que excede la mera concordia pasiva -que puede ser producida y mantenida por el miedo- y la simple ausencia de guerra -que puede ser indistinguible de la soledad y la servidumbre-; mientras la guerra es repetición, la paz es ruptura y novedad -"reintroduce lo nuevo en el mundo", dice Marilena Chauii ${ }^{26}$; una de las tantas libertades que aloja la naturaleza común de los hombres, lo imprevisible mismo que atesora el reino de la necesidad.

${ }^{26}$ Marilena Chaui, Segurança e liberdade: Espinosa e a construçao da paz, "Discurso", 35 (2005), pp. $158-9$.

Araucaria. Revista Iberoamericana de Filosofí, Política y Humanidades, año 16, nº 32. Segundo semestre de 2014. Pp. 93-109. ISSN 1575-6823 e-ISSN 2340-2199 doi: 10.12795/araucaria.2014.i32.05 


\section{Referencias bibliográficas}

\section{Fuentes primarias}

Spinoza, B., Tratado teológico-político, trad. de A. Domínguez, Madrid, Alianza, 1986.

—, Tractatus politicus / Traité politique, texto establecido por Omero Proietti; trad., intr., notas, glosarios, index y bibl. de Ch. Ramond, Paris, Presses Universitaires de France, 2005.

— Tratado político, trad. de A. Domínguez, Madrid, Alianza, 1986.

—

—- Correspondencia, trad. de A. Domínguez, Madrid, Alianza, 1988.

Hobbes, Th., Tratado sobre el ciudadano, edición de Joaquín Rodríguez Feo, Madrid, Trotta, 1999.

— Leviatán, trad. de M. Sánchez Sarto, Madrid, Sarpe, 1983.

Maquiavelo, N., Discursos de la primera década de Tito Livio, trad. de Roberto Raschella, Buenos Aires, Losada, 2003.

\section{Estudios}

Chaui, M. Segurança e liberdade: Espinosa e a construçao da paz, "Discurso", 35 (2005).

—- Desejo, paixão e ação na Ética de Espinosa, São Paulo, Companhia das Letras, 2011.

Morfino, V., Il tempo e l'occasione. L’incontro Spinoza-Machiavelli, Il Filarete, Facoltà di Lettere e Filosofia dell’Universitá di Milano, 2002.

_- Il tempo de la multitudine. Materialismo e politica prima e dopo Spinoza, Roma, Manifestolibri, 2005.

Portinaro, P.-P., Materiali per una storicizzazione della coppia amico-nemico [en Gianfranco Miglio (coord.), Amicus (inimicus) hostis, Milano, Giuffrè Editore, 1992. 
